\title{
Dubious Objections from Iterated Conjunctions
}

\author{
forthcoming, Philosophical Studies \\ Matthew A. Benton \\ mbenton@philosophy.rutgers.edu
}

David Sosa (2009) argues that the supporter of the Knowledge Account of Assertion (KAA) has to explain not only the infelicity of asserting Moorean conjunctions of the form

(1) $p$ but I don't know that $p$

but also conjunctions including iterated claims, as in

(2) $p$ but I don't know whether I know that $p$.

Sosa considers KAA faulty in that it does not generalize to handle assertions such as 22 without appealing to controversial principles such as the "KK" principle (according to which if S knows that $p$ then $S$ also knows that $\mathrm{S}$ knows that $p$ ), and that this presents a problem for KAA. This is thought to be particularly problematic since recent defenders of KAA such as Williamson (2000), Hawthorne (2004), and DeRose (2009, ch. 3), deny the plausibility of $\mathrm{KK}$.

Sosa 2009,270$)$ maintains that the adequacy of KAA's explanation of (1) "is challenged by the oddity of (instances of)" (2): "The knowledge account does not generalize satisfactorily. We do not adequately understand what is wrong with" (1) "if our explanation does not account for what is wrong with" (2).

However this claim overreaches, given two important differences between (1) and (2); and these differences will be of interest even to those who reject KAA. First, knowing-that-one-knows-that- $p$ is plausibly a different thing from knowing-that- $p$. If so then (2) appears to have the form

\footnotetext{
${ }^{1}$ I call these "Moorean conjunctions" rather than "Moore's paradox" because (i) it is important to distinguish them from the original Moorean paradox involving belief, particularly the form " $p$ but I don't believe that $p$ "; and (ii) some (though not I) take instances of 11 to be not at all paradoxical, or at least less paradoxical than the original. Following Sosa, I shall still refer to 1 as "Moorean."
} 
(3) $p$ but I don't know whether [that] $q$,

and it's not clear why such constructions should be thought to admit of, much less require, the same explanation as that given for the Moorean (1). And moreover, sentences like (2) don't seem to clash in the same way that pure Moorean constructions do, even though they definitely sound clunky. ${ }^{2}$ Second, 2) can be known ${ }^{3}$ whereas (1) cannot. So because (1) is Moorean in form and (2) is not, and because (1) cannot be known but (2) can, it's quite unclear that Sosa is correct that KAA's explanation of $(1)$ is inadequate if it cannot generalize to account for (2); for (2) is different from (1) in ways that matter.

Such differences reveal how some contexts can make it appropriate (even if clunky) to assert instances of (2) even though those contexts do not render it appropriate to assert (1). 4 One common enough case is when one suspends judgment on whether one's belief that $p$ amounts to knowledge, which often arises in cases of disagreement: if I believe, and in fact know, that the Giants won the 1954 World Series, but you disagree, your disagreeing with me may lead me to suspend judgment on whether I know. I may thereby lose confidence that I know while nevertheless remaining quite confident that they won; in such a case it can be felicitous (though perhaps clunky) to assert "The Giants won in '54, but I don't know whether I know that," but this same situation would not make it felicitous to assert "The Giants won in '54 but I don't know that they did." Thus (1) and (2) warrant different treatment.

But even if we suppose that I'm wrong about all that, the KAA-theorist can tackle Sosa's concern head-on by showing what is wrong with assertions of (2), and can do so without appealing to principles such as KK; in fact, the problem can be handled twice over. And again, because the conjuncts of 2) can be known, we should expect that the KAA-theorist, whilst still assuming KAA, may have to look beyond its resources to help account for (2)'s infelicity.

First, according to one prominent version of KAA ${ }_{5}^{5}$ by asserting the first conjunct of 22 a speaker represents herself as knowing that $p$. And then in

\footnotetext{
${ }^{2}$ On the distinction between clunks and clashes, see DeRose (2009. 208 n. 17).

${ }^{3}$ As Sosa notes 2009, 270). That its conjuncts can be known provides the KAA-theorist with a good explanation for why 2 would only clunk but not clash: because it can be known, it shouldn't clash as does 11 .

${ }^{4}$ Thanks to an anonymous referee here.

${ }^{5}$ See Moore (1962, 277), Unger 1975, 253), and DeRose (1991, 597-605 and 2009, 93).
} 
asserting the second conjunct, she expresses outright that she doesn't know whether she knows that $p$. But because representing something as being so involves representing that thing as being true, in conversational contexts we will tend to find it irresponsible for someone to represent something as being true if she explicitly claims that she doesn't know whether that thing is true: after all, why, unless she is intentionally trying to mislead, would one represent something as being the case when she doesn't know that it's the case?

Second, even without appealing to such a general principle as the one just sketched, the KAA-theorist can handle the infelicity of (2) by adopting the Express Knowledge Account of Assertion (EKA), according to which one may assert that $p$ only if one's assertion expresses one's knowledge that $p$ (Turri 2011). Tokens of (2) cannot hold up given the EKA, and are easily explained by it: a speaker appropriately asserts its first conjunct only if by doing so she expresses her knowledge that $p$; but then, in asserting the second conjunct, she expresses her ignorance about whether she in fact knows that $p$. Now we are presupposing the falsity of the KK principle; so it is a perfectly possible state of affairs that one know a proposition, express it through speech, yet nonetheless fail to know that one knows it. But a hearer would be given to wonder why one would engage in a speech act meant to express one's knowledge if one is ignorant of whether they have that knowledge; for often enough, when permissibly $\varphi$-ing involves expressing an attitude or mental state which, as far as the agent can tell she may not possess, then she'll be in danger of impermissibly $\varphi$-ing by going ahead and $\varphi$-ing. Thus asserting (2) is apt to strike its hearer as unduly incautious 6

But note that this second strategy is also available to the KAA-theorist unwilling to adopt EKA. For even on the simple knowledge account, wherein knowing a proposition is what positions one for permissible assertion, it is still odd-again, because careless-to acknowledge explicitly that one doesn't know whether one is permitted to make an assertion while at the same time making that very assertion 7

\footnotetext{
${ }^{6}$ As Unger (1975, 262) put it.

${ }^{7}$ Note that these sorts of explanation can also account for the oddity of similar iterated conjunctions provided by Sosa (2009, 271), e.g.

(4) $p$ but I doubt that I know that $p$

(5) $p$ but I believe that I don't know that $p$

(6) $p$ but I have no justification for believing that I know that $p$

(7) $p$ but I have (sufficient) justification for believing that I don't know that $p$
} 
The appeal to carelessness, whether on KAA or on EKA, can be accounted for by deploying the distinction, drawn by DeRose ${ }^{8}$ [2002, 180; 2009, 94-95) between primary and secondary propriety. The knowledge account's norm requiring knowledge of its asserter specifies the primary dimension of propriety: S's assertion that $p$ has primary propriety iff $S$ knows that $p$ (and, on EKA, the assertion expresses that knowledge). But a speaker who does not know yet reasonably believes that she knows and for that reason asserts, violates the norm in a primary sense but nevertheless acts in a secondarily proper way: her assertion is appropriate in the sense that it was made in a reasonable attempt to conform to the norm. One who asserts (2), perhaps because one has suspended judgment on whether one knows that $p$, is secondarily improper in doing so (even if $p$ is known and the assertion is thereby primarily proper); and one who acknowledges this secondary impropriety, as the second conjunct of (2) seems to do, should likewise suspend judgment on whether outright asserting its first conjunct is primarily proper. This explains the carelessness of asserting (2); but it also accounts for its contrast with the assertability of (1), for one who asserts the latter must take it to lack both primary and secondary propriety. 9

Thus the friend of the KAA can account for the infelicity of the type (2) without appealing to the KK principle 10

\section{References}

DeRose, Keith. 1991. "Epistemic Possibilities." The Philosophical Review 100: 581-605.

- 2002. "Assertion, Knowledge, and Context." The Philosophical Review 111: 167-203.

KAA predicts that flat-out asserting the first conjunct as in $4-7$ represents the speaker as knowing that $p$; but it's irresponsible and misleading for a speaker to assert so as to represent herself as knowing while also calling into question that she in fact knows. Such a speaker, in asserting the second conjunct, shows that she shouldn't have flat-out (rather than hedgingly) asserted the first conjunct.

${ }^{8}$ And also by Williamson 2000, 256), though he labels the dimensions "permissibility" and "reasonability".

${ }^{9}$ Thanks to an anonymous referee here.

${ }^{10}$ Thanks to Christoph Kelp, Blake Roeber, Jonathan Schaffer, Ernest Sosa, John Turri, and an anonymous referee for helpful comments. 
- 2009. The Case for Contextualism. Oxford: Clarendon Press.

Hawthorne, John. 2004. Knowledge and Lotteries. Oxford: Clarendon Press.

Moore, G.E. 1962. Commonplace Book: 1919-1953. London: George Allen \& Unwin.

Sosa, David. 2009. "Dubious Assertions." Philosophical Studies 146: 26972.

Turri, John. 2011. "The Express Knowledge Account of Assertion." Australasian Journal of Philosophy 89: 37-45.

Unger, Peter. 1975. Ignorance: A Defense of Skepticism. Oxford: Clarendon Press.

Williamson, Timothy. 2000. Knowledge and its Limits. Oxford: Oxford University Press. 